\title{
Analysis of impaired in vitro immunoglobulin synthesis in rheumatoid arthritis
}

\author{
I Jokinen, K Poikonen, T Möttönen, P Hannonen, M Oka, J Ilonen, Heljä-Marja Surcel, \\ Riitta Karttunen, H Arvilommi
}

\begin{abstract}
Decreased immunoglobulin production in pokeweed mitogen driven lymphocyte cultures has been reported in rheumatoid arthritis (RA). Here various activators and experimental designs have been used to determine the contribution of $B$ cells, $T$ cells, or monocytes to this low response.

Sixty patients with RA and paired controls were studied at the onset of disease and again six months later. Concentrations of $\mathrm{IgA}, \mathrm{IgG}$, and IgM in cultures of RA peripheral blood mononuclear cells stimulated with thymus dependent activators were already decreased at the onset of the disease. Six months later RA mononuclear cells produced even lower concentrations of immunoglobulin. In contrast, stimulation with a $T$ cell independent activator showed that RA B lymphocytes had retained normal potential to synthesise immunoglobulin.

Poor helper function was indicated by costimulation experiments and cultures of mixed mononuclear cells from patients and controls. This notion was supported also by the fact that phytohaemagglutinin induced interleukin-2 production by $R A$ mononuclear cells was less than half of the control values. Nonspecific suppressor activity was similar in RA and controls.
\end{abstract}

Monocyte functions were normal when tested by addition of indomethacin or 2 mercaptoethanol to the mitogen activated cultures.

The defect in mitogen stimulated immunoglobulin production in vitro of RA mononuclear cells thus was more pronounced with time and probably reflects impaired mediator associated help in the differentiation of $B$ lymphocytes into immunoglobulin secreting cells. Microbiology, University of Oulu, SF-90220 Oulu, Finland

$K$ Poikonen

J Ilonen

R Karttunen

Central Hospital, SF-40620 Jyväskylä,

Finland

T Möttönen

P Hannonen

M Oka

Public Health Institute, SF-90220 Oulu, Finland

$\mathrm{H}-\mathrm{M}$ Surcel

Public Health Institute, SF-40620 Jyväskylä, Finland

Finland

Correspondence to:

Dr Jokinen.

Accepted for publication

30 August 1989

There is ample evidence of aberrant imm functions in rheumatoid arthritis (RA), including serum hyperimmunoglobulinaemia and production of autoantibodies. ${ }^{1}$ The mechanisms leading to these abnormalities are still obscure. In vitro culture studies with blood lymphocytes have shown, paradoxically, a decreased mitogen stimulated immunoglobulin secretion. ${ }^{2-6}$ The reasons for decreased immunoglobulin synthesis are unknown. It is also unknown whether these cellular mechanisms are related to B cells, $T$ cells, or monocytes. We have extended these studies and report that this phenomenon becomes more pronounced during six months' follow up of recent onset disease. In this study we also report on experiments designed to determine whether the decreased immunoglobulin production is due to changes in the functions of $B$ cells, $T$ helper or $T$ suppressor cells, or monocytes.

\section{Patients and methods}

PATIENTS AND CONTROLS

The patient group comprised 58 patients ( 17 men, 41 women) with newly diagnosed RA fulfilling American Rheumatism Association criteria for definite or classical RA. The patients were aged 17 to 78 years (mean 48) with a duration of disease of two to 24 months (mean eight). At the onset of the study none of the patients had received second line antirheumatic drugs. During the next six months before the second blood sample 54 patients received intramuscular injections of sodium aurothiomalate $(10,20,30$, and $50 \mathrm{mg}$ weekly up to $13 \mathrm{mg} / \mathrm{kg}$ body weight and thereafter $50 \mathrm{mg}$ monthly), three patients were treated with hydroxycholoroquine (300 $\mathrm{mg}$ daily), and one with a non-steroidal anti-inflammatory drug. If these drugs were not tolerated (12 patients) auranofin, sulphasalazine, D-penicillinamine, or azathioprine was given. Fifty nine healthy laboratory and office personnel (26 men, 33 women) with a mean age of 36 (range 26-61) served as controls.

\section{BLOOD SAMPLES}

Blood samples were taken at the onset of the study and six months later. Blood was collected by venepuncture and treated with heparin (20 $\mathrm{U} / \mathrm{ml}$ preservative free sodium heparin). Mononuclear cells were separated by Ficoll-Paque (Pharmacia Chemicals, Uppsala, Sweden) density gradient centrifugation and washed three times with Hanks's balanced salt solution. Cells were suspended $\left(1 \times 10^{6}\right.$ cells $\left./ \mathrm{ml}\right)$ in RPMI 1640 medium supplemented with $10 \%$ fetal calf serum (Gibco, Scotland), glutamine $3 \mathrm{~g} / \mathrm{l}$, and gentamicin $15 \mathrm{mg} / \mathrm{l}$ (Sigma Chemical Co, USA).

\section{CELL CULTURES}

Mononuclear cells were cultured in microtitre plates of tissue culture grade (Nunc, Denmark) in $200 \mu \mathrm{l}$ volumes stimulated with either pokeweed mitogen diluted 1:100 (Gibco Ltd) or Staphylococcus aureus Cowan I $0.05 \% \mathrm{vol} / \mathrm{vol}$ prepared as described elsewhere. ${ }^{7}$ Pokeweed mitogen stimulated cocultures were set up by mixing equal numbers of RA and control mononuclear cells to give a cell density $1 \times 10^{6} / \mathrm{ml}$ suspension. Hydrocortisone (The Upjohn Co, 
USA) $10^{-5} \mathrm{~mol} / \mathrm{l}$, concanavalin A (Pharmacia Chemicals, Sweden) $4 \mathrm{mg} / \mathrm{l}$, or indomethacin (Lääketehdas Orion, Finland) $1 \mathrm{mg} / \mathrm{l}$ was added directly to cultures. Cells were cultured in a humified $\mathrm{CO}_{2}$ incubator at $37^{\circ} \mathrm{C}$ for seven days. Cultures of $1 \mathrm{ml}$ volume in round bottomed $12 \times 75 \mathrm{~mm}$ plastic tubes (Sterilin, England) were stimulated with 1:4 vol/vol Epstein-Barr virus containing B95-8 marmoset cell culture supernatant, filtered through a $0.45 \mu \mathrm{m}$ nitrocellulose filter (Schleicher and Schuell, Germany), and stored for a maximum of three months in a refrigerator.

\section{ELISA MEASUREMENT OF IMMUNOGLOBULIN PRODUCTION}

Supernatants from cultures were stored frozen at $-20^{\circ} \mathrm{C}$. Immunoglobulin concentration was determined by a double antibody sandwich enzyme linked immunosorbent assay (ELISA) method $^{2}$ using isotype specific trapping and alkaline phosphatase conjugated isotype specific detecting antibodies (Orion Diagnostica, Finland). Measurements were standardised with known concentrations of standard sera (Behringwerke, Germany). The absorbances were read with a Titertek Multiscan plate reader (Flow Laboratories).

\section{PRODUCTION AND DETERMINATION OF}

INTERLEUKIN-2

Mononuclear cells $\left(1.5 \times 10^{6}\right)$ were cultured for 24 hours with phytohaemagglutinin (Difco Laboratories, USA) 1:100 final dilution in $1 \mathrm{ml}$ of RPMI 1640 medium supplemented with $10 \%$ fetal calf serum, glutamine $3 \mathrm{~g} / \mathrm{l}$, and gentamicin $15 \mathrm{mg} / \mathrm{l}$. Cell free supernatants were harvested by centrifugation and stored frozen at $-20^{\circ} \mathrm{C}$. The samples were assayed for interleukin-2 (IL-2) by an IL-2 dependent murine cytotoxic T cell line CTLL- ${ }^{8}$ or concanavalin A stimulated lymphocytes. ${ }^{9}$ The assays of patients with RA and controls were performed simultaneously, and the values for RA samples were calculated as a percentage of the mean of controls.

\section{STATISTICAL METHODS}

Student's $t$ test and the Mann-Whitney U test were used to determine statistical significance.

\section{Results}

IMMUNOGLOBULIN SECRETION BY MITOGEN STIMULATED MONONUCLEAR CELLS

We used ELISAs to measure immunoglobulin isotypes in supernatants of seven day cultures of blood mononuclear cells at the onset of disease and six months later. Two polyclonal stimulants were used: pokeweed mitogen, a strictly monocyte and $\mathrm{T}$ cell dependent mitogen, ${ }^{10}{ }^{11}$ and $S$ aureus Cowan I, which is considered to be a B cell activator fairly independent of $\mathrm{T}$ cells. Yet the differentiation of cells activated by $S$ aureus Cowan I is reported to depend on T cells. ${ }^{12} 13$ At the onset of the disease production of immunoglobulin was already decreased in RA and at six months the defect had become greater in all isotypes (fig 1). Both mitogens seemed to show the defect similarly. Unstimulated RA mononuclear cells, however, produced similar amounts of immunoglobulin to those of healthy controls (fig 1).

Epstein-Barr virus, a direct $\mathrm{B}$ cell activator, ${ }^{11}$ did not stimulate secretion of IgA and IgG, but the concentration of IgM was increased two- to 10 -fold compared with unstimulated cultures. There was no significant difference between RA and control mononuclear cells in production of IgM either at the onset of the study or after six months (data not shown).

TESTS OF SUPPRESSOR AND HELPER FUNCTIONS Hydrocortisone in physiological and pharmacological concentrations causes a marked enhancement of immunoglobulin secretion in cultures stimulated with pokeweed mitogen. ${ }^{14}$ It is suggested that this effect is due to modulation of the triggering signal for $B$ cells by naturally occurring suppressor $\mathrm{T}$ cells ${ }^{15}$ or $\mathrm{T}^{+} \mathrm{T}$ cells. ${ }^{16}$ Figure 2 shows the effect of $10^{-5} \mathrm{~mol} / \mathrm{l}$ hydrocortisone on immunoglobulin secretion by RA and control mononuclear cells. The results are expressed as the ratio of hydrocortisone supplemented/unsupplemented cultures stimulated either with pokeweed mitogen or $S$ aureus Cowan I. The relative increase of immunoglobulin secretion by hydrocortisone in pokeweed
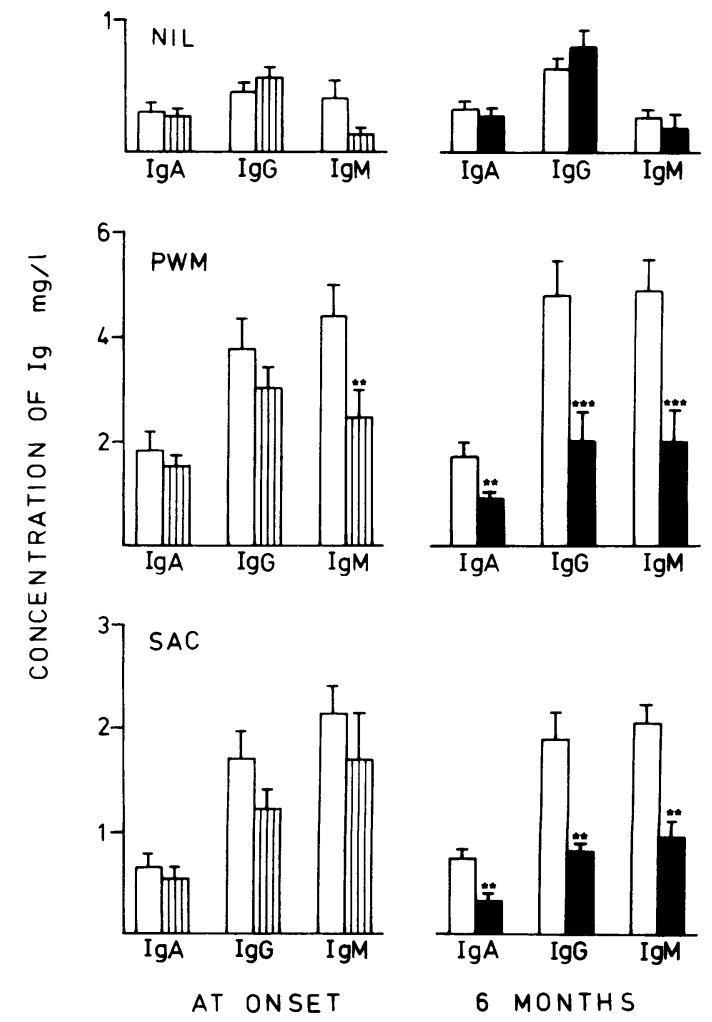

Figure 1: Production of IgA, IgG, and IgM in cultures of seven days of blood mononuclear cells. Open bars represent healthy controls, striped bars patients with rheumatoid arthritis $(R A)$ at the onset of the study, and black bars patients with $R A$ six months later. The cultures were unstimulated (NIL), stimulated with pokeweed mitogen (PWM ), or with Staphylococcus aureus Cowan I (SAC). $(P W M)$, or with Staphylococcus aureus Cowan I (SAC).
Results are expressed as the mean $(S E M)$, for $R A n=60$, for controls $n=57$ at the onset and $n=47$ six months later. $* * p<0.01 ; * * * p<0 \cdot 001$. 


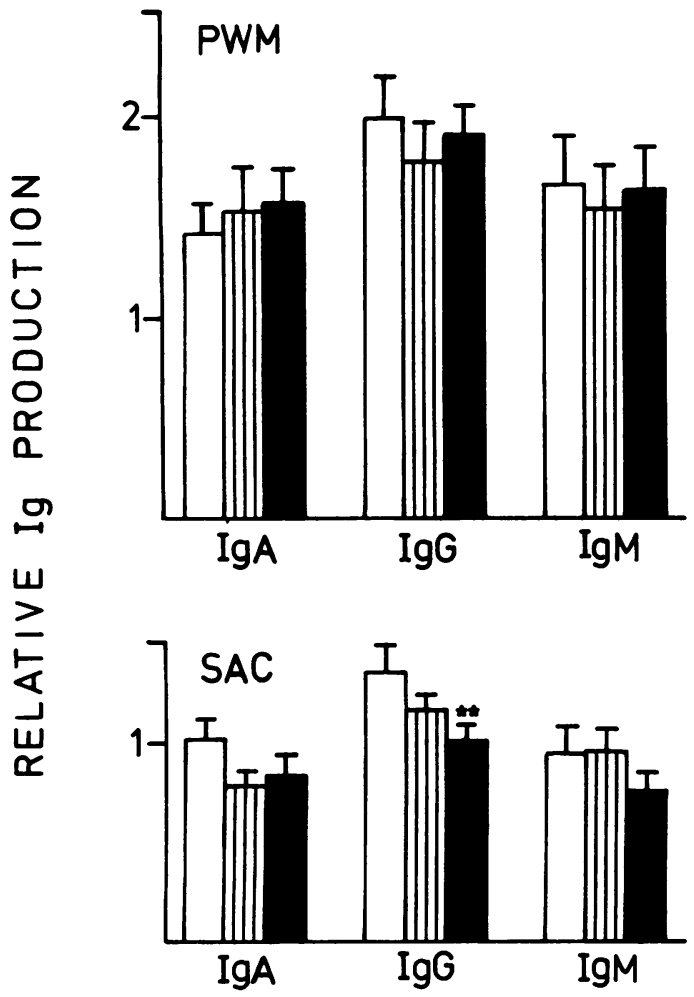

Figure 2: The effect of hydrocortisone $10^{-5} \mathrm{~mol} / \mathrm{l}$ on pokeweed mitogen (PWM) or Staphylococcus aureus Cowan $I(S A C)$ stimulated cultures of healthy subjects (open bars), patients with rheumatoid arthritis $(R A)$ at the onset of the study (striped bars), and patients with $R A$ after six months (black bars). The results are expressed as the mean (SEM) of the ratio calculated from the concentrations in hydrocortisone supplemented/unsupplemented culture supernatants in cultures of seven days. The numbers of subjects were $n=50$ for controls and $n=54$ for patients with $R A .{ }^{* *} p<0 \cdot 01$.
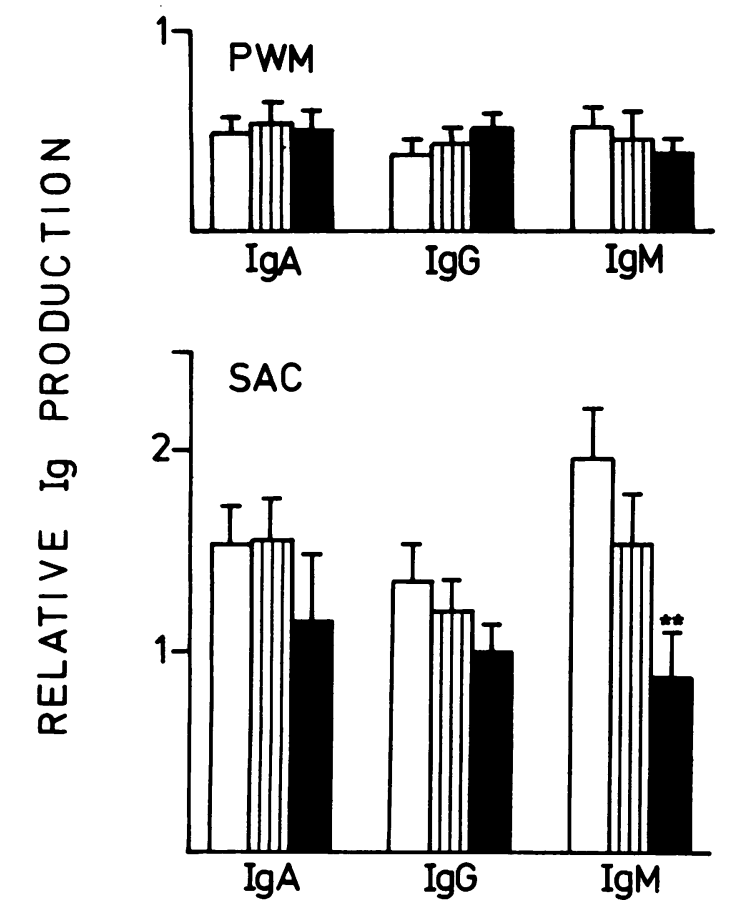

Figure 3: The effect of concanavalin A costimulation on the immunoglobin production stimulated with pokeweed mitogen (PWM) or Staphylococcus aureus Cowan I (SAC) in mononuclear cell cultures of controls (open bars), patient with rheumatoid arthritis (RA) at the onset of the study (striped bars), and patients with $R A$ six months later (black bars). The results are expressed as the mean (SEM) of the ratio concanavalin $A$ costimulated/unstimulated

immunoglobulin production in culture supernatants of seven days. The numbers of subjects were $n=34$ for controls and $n=23$ for patients with $R A .{ }^{* *} p<0 \cdot 01$. mitogen stimulation was similar in RA and control mononuclear cells. When hydrocortisone was added to RA mononuclear cells the reduced immunoglobulin secretion was not restored to the level of controls.

In contrast with pokeweed mitogen stimulated cultures, the addition of hydrocortisone to cultures stimulated with $S$ aureus Cowan I did not enhance immunoglobulin secretion. Interestingly, the mononuclear cells of the patients produced less immunoglobulin than the controls; this was most noticeable for IgG. This defect was greater later in the course of the disease (fig 2).

Concanavalin A may also be used to study non-specific suppressor activity. It is claimed to suppress pokeweed mitogen stimulated immunoglobulin synthesis by triggering suppressor precursor cells, which are then converted into effectors by pokeweed mitogen. ${ }^{17}$ As seen in fig 3 concanavalin A reduced equally pokeweed mitogen driven immunoglobulin secretion by both the RA and control mononuclear cells. Again, $S$ aureus Cowan I, costimulated with concanavalin A, produced quite a different pattern. Instead of inducing suppression, concanavalin A increased immunoglobulin secretion 35 to $100 \%$ in control mononuclear cells (fig 3). In RA, however, this increase was not as prominent and indeed, at six months did not occur at all. A difference between RA and control responses was found in all immunoglobulin classes but reached statistical significance for IgM.

Mononuclear cells from patients with RA and healthy controls were stimulated with pokeweed mitogen and cocultured in equal numbers to find out whether decreased immunoglobulin synthesis was due to defective helper function or increased suppression. The concentration of immunoglobulin obtained in the coculture was compared with the mean concentration in cultures from each donor separately, and the ratio of observed to expected was calculated. Ratios of observed/expected over 1.0 would point to subnormal helper function, whereas ratios below 1.0 would be due to activation of suppressor T cells. ${ }^{1819}$ The mean observed/expected values at onset were close to unity, but after six months the values increased to $1 \cdot 12$ for IgA and $1 \cdot 22$ for IgG and IgM, suggesting poor helper effect in RA (table 1).

INTERLEUKIN-2 PRODUCTION

Disturbances in the production of soluble mediators of cellular cooperation might be another reason for impaired immunoglobulin

Table 1: Mean observed/expected values for immunoglobulin production in pokeweed mitogen stimulated cocultures of control mononuclear cells with those from another contro (control) and for mononuclear cells from a patient with rheumatoid arthritis with control mononuclear cells $(R A)$

\begin{tabular}{lllll}
\hline Group & $n$ & \multicolumn{3}{l}{ Observed/expected } \\
\cline { 3 - 5 } & & $I g A$ & $I g G$ & $I g M$ \\
\hline Control & 30 & 0.99 & 0.95 & 0.86 \\
RA-at onset & 54 & 0.96 & 0.97 & 1.06 \\
-at 6 months & 43 & 1.12 & 1.22 & 1.22 \\
\hline
\end{tabular}


Table 2: Phytohaemagglutinin stimulated interleukin-2 production in mononuclear cell cultures of controls and patients with rheumatoid arthritis $(R A)$. The results are expressed as a percentage of the mean of controls $(S D)$

\begin{tabular}{lll}
\hline Group & $n$ & Interleukin-2 \\
\hline Control & 52 & $100(193)$ \\
RA-at onset & 53 & $85(155)$ \\
-at 6 months & 49 & $42(60)^{*}$ \\
\hline
\end{tabular}

${ }^{*}$ Significantly different from controls, $\mathrm{p}<0 \cdot 01$.

production. We chose to investigate IL-2, a mediator of $T$ cell origin, because of its central role in cellular activation and differentiation. Supernatants from phytohaemagglutinin stimulated 24 hour mononuclear cell cultures of RA at the onset of the study contained $15 \%$ less IL2 than controls (table 2). The amount of IL-2 found in culture supernatants of RA mononuclear cells was even lower after six months, being only $42 \%$ of the concentration of IL-2 in controls. The phytohaemagglutinin stimulated IL-2 production by controls, when the results in count per minute were converted to $\mathrm{U} / \mathrm{ml}$ using an IL-2 standard of known concentration, was similar to those reported earlier. ${ }^{20}$

\section{TESTS OF MONOCYTE FUNCTION}

Monocytes are the major source of prostaglandins, which among other things influence immunoglobulin synthesis. ${ }^{2122}$ Therefore, defects in the production of prostaglandins might contribute to the decreased immunoglobulin response in RA. If this were the case, prostaglandin inhibitors would decrease immunoglobulin secretion by healthy lymphocytes more than that by RA lymphocytes. When indomethacin was added to cultures of mononuclear cells the effect was similar in RA and control cells stimulated by pokeweed mitogen or $S$ aureus Cowan I (data not shown), with no significant difference.

It has been claimed that the accessory function in in vitro IgG secretion of RA monocytes is impaired and that this impairment may be restored by addition of 2-mercaptoethanol, which modifies cell surface sulphydryl groups. ${ }^{23}$ We therefore tested 2-mercaptoethanol in cultures driven by pokeweed mitogen and $S$ aureus Cowan I but found no enhancing effect (data not shown).

\section{Discussion}

Rheumatoid arthritis is a disease of unknown cause with features of autoimmunity. In vitro tests of RA lymphocytes have shown perturbed immunofunctions. ${ }^{1}$ In contrast with the increased serum immunoglobulin concentrations in $\mathrm{RA}$, mitogen driven immunoglobulin production has been reported to be depressed. ${ }^{2-6}$ Here we have shown that this defect in immunoglobulin production is already present at the onset of disease and more pronounced during the disease. Furthermore, our experiments suggest impaired mediator production as the most plausible mechanism for this defect.

Synthesis of immunoglobulin by B lymphocytes/plasma cells after stimulation with pokeweed mitogen is under the control of $\mathrm{T}$ helper and $T$ suppressor cells and is also monocyte dependent. 111 Thus the noted defect may result from disturbances in any of these individual cell subsets. $S$ aureus Cowan I does not activate $T$ suppressor cells, but full differentiation into plasma cells depends on $\mathrm{T}$ cell cooperation. ${ }^{121324}$ The fact that both mitogens, despite differences in the $T$ suppressor control, show an equal defect in immunoglobulin production by RA lymphocytes suggests that $T$ suppressors are not the cause. Indeed we were unable to show changes in suppressor functions of RA cells in more direct tests with hydrocortisone or concanavalin $A$ in pokeweed mitogen cultures or with cocultures of RA and control cells. Similarly, B lymphocytes of patients with RA seem to have retained their normal potential to produce immunoglobulin as synthesis of immunoglobulin, driven by Epstein-Barr virus, is unimpaired. This is in agreement with an earlier report. ${ }^{25}$ Furthermore, our experiments on monocyte function also gave negative results. Secretion of prostaglandins by monocytes may regulate $B$ cell growth and differentiation by routes which are not yet completely clear. ${ }^{22}$ Inhibition of prostaglandin synthesis by indomethacin had similar effects on immunoglobulin secretion in patients and controls, indicating normal function of RA monocytes. Hence we conclude that $B$ cells, monocytes, and $T$ suppressor cells show no abnormalities in our tests, though we realise that all possible defects in these subsets of cells cannot be excluded with these experiments.

Helper functions, on the other hand, seem abnormal in this study. Firstly, we found that IL-2 secretion induced by phytohaemagglutinin was significantly reduced compared with controls, in agreement with earlier studies. ${ }^{26} 27$ Increased IL-2 production in RA has also been reported, however. ${ }^{28} 29$ The reduction of IL-2 secretion became more obvious at the same time as the reduction of immunoglobulin production during six months' follow up. Secondly, in cocultures of RA and control cells high observed/expected values indicate that low pokeweed mitogen responses of RA cells are augmented by help from control cells or factors. Thirdly, concanavalin A in the cultures stimulated with $S$ aureus Cowan I increased the production of immunoglobulin in controls in this study. It is known that concanavalin A induces secretion of IL-2 and probably other mediators as well. It has also been shown that IL-2, and even more so mediators in $\mathrm{T}$ cell supernatants, stimulate proliferation and differentiation of B cells activated with $S$ aureus Cowan I. $^{12}$ Therefore the concanavalin A induced increase of immunoglobulin production might most simply be explained by the effects of increased mediators on the differentiation of cells activated by $S$ aureus Cowan $I$. That this increase does not occur in RA suggests defective mediator associated help or a lack of cell subsets responsible for their production. Cells bearing CD4 are thought to contain the principal IL-2 producing lymphocytes. ${ }^{30}$ The only cells among $\mathrm{CD}^{+}$lymphocytes able to produce IL- 2 are of the phenotype $\mathrm{CD} 4^{+} 2 \mathrm{H} 4^{+}$ 4B4 ${ }^{-31-33}$ Recently, a specific loss of this 
subset has been shown to occur in RA, which may be relevant. ${ }^{34} 35 \mathrm{~A}$ weak proliferation of the true helper subset $\mathrm{CD}^{+} 2 \mathrm{H}^{-} 4 \mathrm{H}^{+}$owing to depressed IL-2 production may lead to low activation and especially poor production of differentiation factors for B cells. It should be pointed out, however, that it is unclear which cells are responsible for mediator production after concanavalin A or $S$ aureus Cowan I stimulation.

Thus we conclude that the most probable mechanism for the defect in in vitro immunoglobulin synthesis in RA is impaired production of IL-2 and, possibly, other mediators. What then might be the cause of abnormal mediator function is another question. Our findings show that during the first six months of the disease the defect in immunoglobulin synthesis becomes more pronounced, which suggests an association with the progress of the disease or, alternatively, with the drug treatment. At the onset of the study the patients did not receive any second line antirheumatic drugs but, nevertheless, showed depressed immunoglobulin production. Non-steroidal anti-inflammatory drugs might have been used, however. The effect of these drugs is currently under investigation in our laboratory.

This work was supported by the Academy of Finland. The Epstein-Barr virus containing B95-8 marmoset cell culture was kindly provided by Professor G Klein, department of tumour biology of the Karolinska Institutet, Stockholm, Sweden.

1 Gupta S, Talal N, eds. Immunology of rheumatic diseases. New York: Plenum Medical Books, 1985.

2 Poikonen K, Oka M, Möttönen T, Jokinen I, Arvilommi H. Synthesis of $\operatorname{IgM}$, IgG, and $\operatorname{IgA}$ in rheumatoid arthritis. Ann Rheum Dis 1982; 41: 607-11.

3 Panush R, Katz P, Longley S. In vitro immunoglobulin production by mononuclear cells in rheumatoid arthritis. Clin Immunol Immunopathol 1983; 28: 252-64.

4 Heilmann C, Peterssen J. Secretion of immunoglobulins and IgM rheumatoid factor by pokeweed mitogen-induced blood lymphocytes: an evaluation by plaque forming cell assays. Acta Pathol Microbiol Immunol Scand [C] 1984; 92: assays.

5 Pardo I, Carafa C, Dziarski R, Levinson A I. Analysis of in vitro polyclonal $B$ cell differentiation responses to bacterial peptidoglycan and pokeweed mitogen in rheumatoid arthritis. Clin Exp Immunol 1984; 56: 253-62

6 Boling E P, Ohishi T, Wahl M, Misiti J, Wistar R Jr, Wilde $R \mathbf{L}$. Humoral immune function in severe, active rheumatoid arthritis. Clin Immunol Immunopathol 1987; 43: 185-94.

7 Forsgren A, Svedlund A, Wigzell H. Lymphocyte stimulation by protein $A$ of Staphylococcus aureus. Eur 7 Immunol 1976; 6: 207

8 Gillis S, Ferm M M, Ou W, Smith $\mathrm{K}$ A. T cell growth factor: parameters of production and a quantitative microassay for parameters of production and a quantita

9 Karttunen R, Nurmi T, Ilonen J, Surcel H-M. Cell-mediated immunodeficiency in Down's syndrome: normal IL-2 production but inverted ratio of T cell subsets. Clin Exp production but inverted ratio

10 Rosenberg S A, Lipsky P E. Monocyte dependence of pokeweed mitogen-induced differentiation of immunoglobulin secreting cells from human peripheral blood mononuclear cells. F Immunol 1979; 122: 926-31.

11 Waldmann T A, Broder S. Polyclonal B-cell activators in the study of the regulation of immunoglobulin synthesis in the human system. Adv Immunol 1982; 32: 1-63.

12 Jelinek D F, Lipsky P E. Regulation of human B lymphocyte activation, proliferation, and differentiation. Adv Immunol 1988; 40: 1-59.

13 Pryima J, Munoz J, Galbraith R M, Fudenberg H H, Virella $G$. Induction and suppression of immunoglobulin synthesis in cultures of human lymphocytes: effect of pokeweed mitogen and Staphylococcus aureus Cowan I. $\mathcal{f}$ Immunol 1980; 124: 656-61.

14 Fauci S S, Pratt K R, Whalen G. Activation of human lymphocytes. IV. Regulatory effects of corticosteroids on the triggering signal in the plaque-forming response of hum activation. F Immunol 1977; 119: 598-603.

15 Haynes B F, Fauci A S. Mechanisms of corticosteroid action on lymphocyte subpopulations. IV. Effects of in vitro hydrocortisone on naturally occurring and mitogen-induced suppressor cells in man. Cell Immunol 1979; 44: 157-68.

16 Paavonen T. Glucocorticoids enhance the in vitro Ig synthesis of pokeweed mitogen-stimulated human B cells by inhibiting the suppressive effect of $\mathrm{T}^{+}{ }^{+} \mathrm{T}$ cells. Scand $\mathcal{F}$ Immunol 1985; 21: 63-71.

17 Haynes B F, Fauci A S. Activation of human B lymphocytes. III. Concanavalin A-induced generation of suppressor cells of the plaque-forming cell response of normal human $B$ lymphocytes. F Immunol 1977; 118: 2281-7.

18 Jones B M. Clinical evaluation of B-cell and T-regulator cell function using a protein A haemolytic plaque assay. Clin function using a protein A haem

19 Jones B M, Teng C S, Yeung T T. Evaluation of B-cell, T helper-cell, and $\mathrm{T}$ suppressor-cell function in patients with Graves disease before and after treatment with anti-thyroid drugs. Clin Immunol Immunopathol 1982; 25: 232-42.

20 Combe B, Pope R M, Fischbach M, Darnell B, Baron S, Talal N. Interleukin-2 in rheumatoid arthritis: production of and response to interleukin-2 in rheumatoid synovial fluid, synovial tissue and peripheral blood. Clin Exp Immunol 1985; 59: 520-8.

21 Ceupens J L, Goodwin J S. Endogenous prostaglandin E enhances polyclonal immunoglobulin production by tonically inhibiting $T$ suppressor cell activity. Cell Immunol 1982; 70: 41-54.

22 Staite N D, Panayi G S. Prostaglandin regulation of Blymphocyte function. Immunology Today 1984; 5: 175-8.

23 McKeown M J, Hall N D, Corvalan J R F. Defective monocyte function due to surface sulphydryl $(\mathrm{SH})$ oxidation in rheumatoid arthritis. Clin Exp Immunol 1984; 56: 607-13.

24 Pryima J, Pituch-Noworolska A, Flad H D, Ulmer A J, Ernst M. Suppression of Staphylococcus aureus Cowan I-induced immunoglobulin synthesis in vitro: discrimination between the presence of suppressor $T$ cell precursors and effectors. the presence of suppressor T cell precur

25 Segond P, Delfraissy J F, Galnaud P, Wallon C, Massias P, Dormont J. Depressed primary in vitro antibody response in rheumatoid arthritis. Clin Exp Immunol 1979; 37: 196-204.

26 Waalen K, Förre Ö, Linker-Israeli M, Thoen J. Evidence of an activated $T$-cell system with augmented turnover of interleukin 2 in rheumatoid arthritis. Scand $\mathcal{F}$ Immunol 1987; 25: 367-73.

27 Kitas G D, Salmon M, Farr M, Gaston J H S, Bacon P A. Deficient interleukin 2 production in rheumatoid arthritis: association with active disease and systemic complications. Clin Exp Immunol 1988; 73: 242-9.

28 Wolf $R$ E, Hall $V$. Interleukin-2 production and effect of thymosin fraction 5 on interleukin-2 production in rheumatoid arthritis. I R heumatol 1987; 14: 898-901.

29 Warrington R J. Interleukin-2 abnormalities in systemic lupus erythematosus and rheumatoid arthritis. A role for overproduction of interleukin-2 in human autoimmunity? f Rheumatol 1988; 15: 616-20.

30 Moretta A. Frequency and surface phenotype of human T lymphocytes producing interleukin-2. Analysis by limiting dilution and cell cloning. Eur f Immunol 1986; 15: 148.

31 Morimoto C, Letvin N L, Distaso J A, Aldrich W $R$, Schlossman S F. The isolation and characterization of the human suppressor inducer T cell subset. F Immunol 1985; human suppress $1508-15$.

32 Morimoto C, Letvin N L, Boyd A W, et al. The isolation and characterization of the human helper inducer $\mathrm{T}$ cell subset. characterization of the human hel

33 Salmon M, Kitas G D, Gaston J S, Bacon P A. Interleukin-2 production and response by helper $\mathrm{T}$-cell subsets in man. Immunology 1988; 65: 81-5.

34 Lasky H P, Bauer K, Pope R M. Increased helper inducer and decreased suppressor inducer phenotypes in the rheumatoid joint. Arthritis Rheum 1988; 31: 52-9.

35 Emery P, Gentry K C, Mackay I, Muirden K D, Rowley M. Deficiency of the suppressor inducer subset of $\mathrm{T}$ lymphocytes in rheumatoid arthritis. Arthritis Rheum 1987; 30: 849-56. 